\title{
Flutuação populacional da cigarrinha-do-milho em duas localidades do Mato Grosso do Sul
}

\author{
Population fluctuation of leafhopper of corn in two localities of Mato Grosso do Sul State
}

\author{
Crébio José ÁvilaI Carla Cristina Marques Arce ${ }^{I I}$
}

\begin{abstract}
- NOTA -
RESUMO

A cigarrinha-do-milho, Dalbulus maidis (DeLong \& Wolcott, 1923) (Hemiptera: Cicadellidae), é considerada uma das pragas mais importantes da cultura por causar danos devido à sucção de seiva e pela transmissão de patógenos às plantas. Este trabalho teve como objetivo conhecer a flutuação populacional de $\boldsymbol{D}$. maidis em duas localidades do Estado de Mato Grosso do Sul. Cartões adesivos amarelos de dupla face $(7 \times 12 \mathrm{~cm})$ foram instalados, a cada quinze dias, em suportes

cultivated with corn in Dourados and Ponta Porã, MS and stayed in the area for seven days. The same kind of traps was also installed in a grass-plot of Dourados, MS without corn crop nearby. Two peaks of leafhopper were observed being one during the dry period (the period without corn in the field between July and September) and the other during summer (between December and January). Stick traps installed at $0.5 \mathrm{~m}$ above soil surface did capture significantly more leafhopper than the ones installed at $1.5 \mathrm{~m}$ if we consider all sampling carried out during the two years of study.
\end{abstract} de madeira a 0,50 e 1,50m acima do nível do solo, em áreas cultivadas com milho em Dourados e Ponta Porã, MS, permanecendo no campo por sete dias. O mesmo tipo de armadilha foi também instalado em uma área de gramado do município de Dourados, onde não se cultivava milho nas proximidades. Foram constatados dois picos populacionais da cigarrinha nas áreas de monitoramento, sendo um observado no período seco da entressafra de milho (julho a setembro) e outro no verão (dezembro a janeiro). As armadilhas adesivas instaladas na altura de $0,50 \mathrm{~m}$ capturaram significativamente um maior número de cigarrinhas do que a $1,5 \mathrm{~m}$, considerando-se todas as amostragens realizadas nos dois anos.

Palavras-chave: Dalbulus maidis, dinâmica populacional, amostragem, Zea mays.

\section{ABSTRACT}

The leafhopper of corn, Dalbulus maidis (DeLong \& Wolcott, 1923) (Hemiptera: Cicadelidae), is considered one of the main corn pest due to its damage of sap suction and disease transmission to plants. This work had the aim to get information about population fluctuation of $\mathbf{D}$. maidis in the Southern region of Mato Grosso do Sul State. Yellow stick cards of double side ( 7 by $12 \mathrm{~cm}$ ) were installed fortnightly on a wood frame of $0.5 \mathrm{~m}$ and 1.5 above soil surface within areas
Key words: Dalbulus maidis, population dynamics, sampling, Zea mays.

A cigarrinha-do-milho, Dalbulus maidis (DeLong \& Wolcott, 1923) (Hemiptera, Cicadellidae), tem sido relatada como a única espécie de Dalbulus que ocorre no Brasil (OLIVEIRA, 1996), sendo que a sua distribuição geográfica abrange desde a Região Sul dos Estados Unidos até o Norte da Argentina (NAULT, 1990; OLIVEIRA\& LOPES, 2004).

Na cultura do milho, $\boldsymbol{D}$. maidis é considerada uma das pragas mais importantes, podendo causar perdas de produtividade devido à sucção de seiva nas plantas (BUSHING \& BURTON, 1974). Essa praga pode também acarretar danos à cultura pela transmissão de vírus (Maize rayado fino marafivirus-MRFV) e dos molicutes: fitoplasma (Mayze Bush Stunt PhytoplasmaMBSP) e espiroplasma (Corn Stunt Spiroplasma-CST) (NAULT, 1980; HRUSKA \& PERALTA, 1997).

IEmbrapa Agropecuária Oeste, Rodovia Dourados-Caarapo, km 05, Zona Rural, CP 661, 79804-970, Dourados, MS, Brasil. Email: crebio@cpao.embrapa.br. Autor para correspondência.

IDepartamento de Ciências Biológicas, Universidade Estadual de Mato Grosso do Sul (UEMS), Dourados, MS, Brasil. 
O crescimento das áreas cultivadas com milho “safrinha”, notadamente na Região Centro-Oeste do Brasil, vem contribuindo para o aumento das populações e, conseqüentemente, das doenças cujos patógenos a cigarrinha é vetor (OLIVEIRA et al., 1998). O entendimento da dinâmica populacional dessa praga em áreas de cultivo de milho, regionalmente, fornecerá subsídios para a implantação do manejo dessa praga na cultura (OLIVEIRA, 2000). Este trabalho teve como objetivo conhecer a flutuação populacional de $\boldsymbol{D}$. maidis em duas alturas de coleta e duas áreas cultivadas com milho e outra com gramado da Região Sul de Mato Grosso do Sul.

Os estudos de flutuação populacional de D. maidis foram realizados nos municípios de Dourados e Ponta Porã, MS, durante os anos de 2001 e 2002. Para isso, quinzenalmente, armadilhas constituídas por cartões adesivos amarelos de dupla face ( 7 x 12cm) foram instaladas a $0,50 \mathrm{~m}$ e $1,50 \mathrm{~m}$ acima do nível do solo, em um mesmo suporte de madeira, nas áreas cultivadas com milho na época de verão (novembro a fevereiro) e de safrinha (fevereiro a julho). O mesmo tipo de armadilha foi também instalado em uma área de gramado do município de Dourados onde não se cultivava milho nas proximidades para verificar uma possível rota de migração deste inseto, que tem o milho como hospedeiro único. Foram utilizadas cinco armadilhas em cada local de amostragem, as quais foram instaladas distanciadas cerca de 30m uma da outra. Após sete dias no campo, as armadilhas foram retiradas e levadas ao laboratório para contagem das cigarrinhas (adultos + ninfas) que ficavam aderidas ao cartão adesivo. Os valores médios mensais do número de cigarrinhas capturado em cada localidade de amostragem foram representados graficamente. Os valores do número de cigarrinhas capturadas em cada altura $(0,5 \mathrm{~m}$ e $1,5 \mathrm{~m})$ foram comparados pelo teste $\mathrm{t}$ ao nível de 5\% de probabilidade de erro.

Nas áreas cultivadas com milho em Dourados e Ponta Porã, foram observados dois picos populacionais da cigarrinha durante os dois anos consecutivos de levantamento (Figura 1). Em Dourados, as maiores densidades populacionais foram observadas em setembro e agosto, respectivamente, para os anos 2001 e 2002. Em Ponta Porã, foram observados dois picos populacionais da cigarrinha, em julho e em dezembro de 2001, e com menor intensidade daqueles constatados em Dourados. Considerando-se todo o período em que o estudo foi realizado, verificou-se, na área de Ponta Porã, uma menor densidade populacional da cigarrinha quando comparadas às coletas realizadas na área de Dourados (Figura 1). Na área de gramado de Dourados, foi constatado um pico acentuado de coleta de cigarrinha durante o mês de setembro (Figura 2), à semelhança do observado na área de milho desta mesma localidade (Figura 1), apesar da menor densidade de cigarrinhas coletadas.

Nas áreas de Dourados (milho e gramado), as maiores densidades populacionais da cigarrinha coincidiram com o período de seca, que ocorreu após a colheita de milho safrinha, enquanto que em Ponta Porã

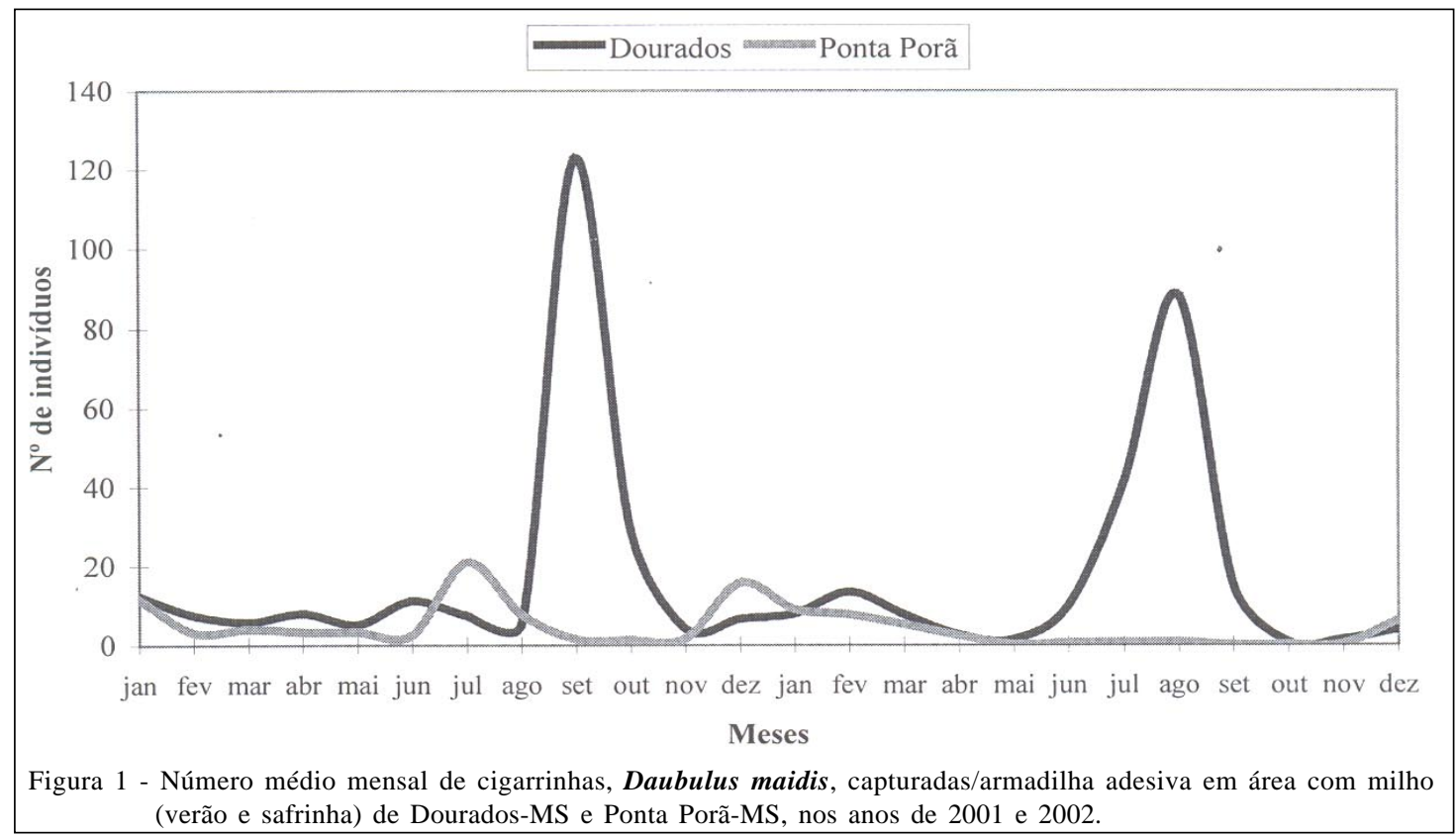

Ciência Rural, v.38, n.4, jul, 2008. 


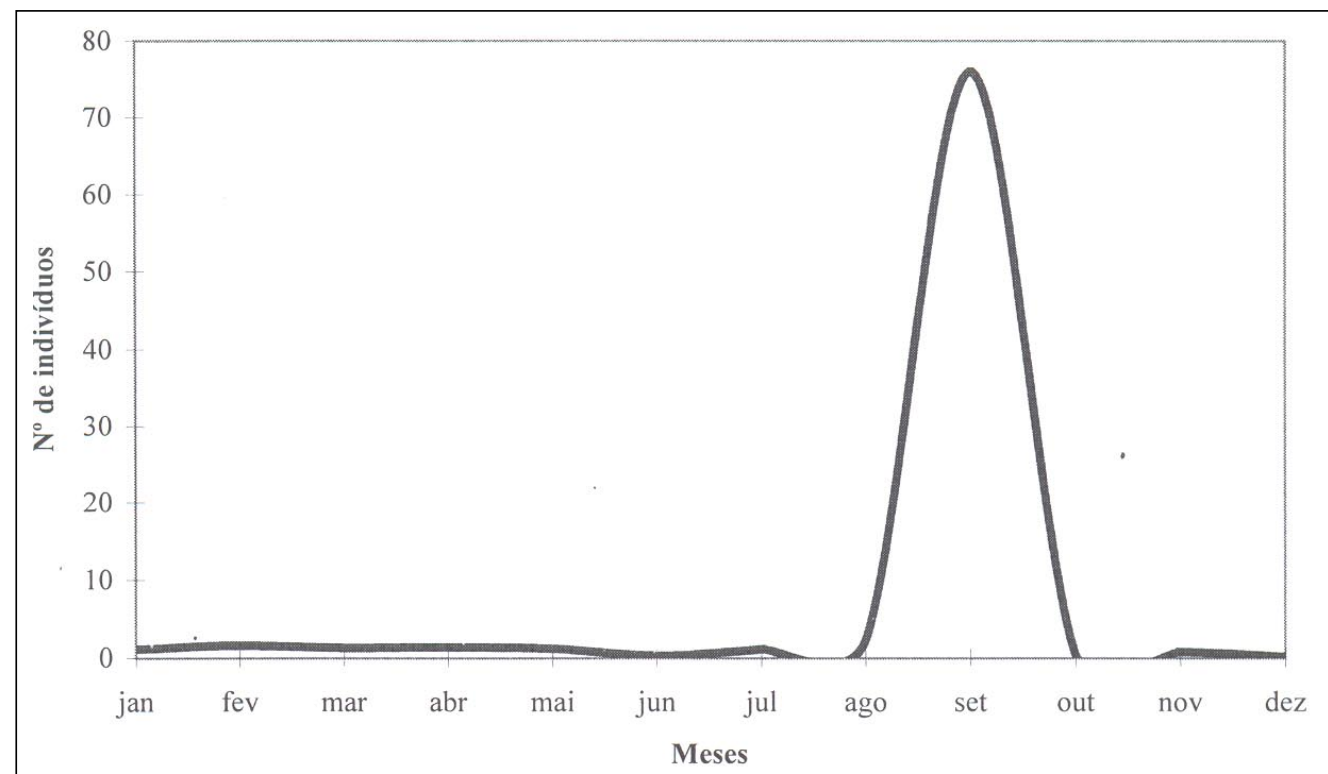

Figura 2 - Número médio mensal de cigarrinhas, Daubulus maidis, capturadas/armadilha adesiva em área de gramado de Dourados-MS, em 2001.

o primeiro pico ocorreu no período seco e o segundo, ocorreu no período chuvoso. OLIVEIRA \& LOPES (2004) relataram que, em uma área cultivada com milho no município de Anastácio-MS, D. maidis foi capturado em armadilhas adesivas no período seco de entressafra da cultura, entre os meses de abril e outubro de 1998 e 1999, à semelhança do verificado neste trabalho. No México, MOYA-RAYGOZA(1993) também constatou que $\boldsymbol{D}$. maidis foi mais abundante durante o período da estação seca, entre os meses de setembro e fevereiro, enquanto que HERNANDEZ-VAZQUEZ et al. (1992) observaram dois picos populacionais: um em outubro, quando o milho encontrava-se na fase reprodutiva e outro, mais acentuado, em janeiro, durante o período seco, quando a cultura já havia completado o seu ciclo. OLIVEIRA (2000) também observou capturas de $\boldsymbol{D}$. maidis no período de entressafra em áreas de pastagens do município de Anastácio-MS, onde o milho não era cultivado há mais de cinco anos.

A captura média mensal de cigarrinhas nas armadilhas adesivas instaladas a 0,50m de altura foi significativamente superior àquela observada nas armadilhas instaladas a 1,50m, tanto nas áreas de cultivo de milho de Dourados e Ponta Porã quanto na área de gramado, considerando-se todas as amostragens realizadas nos dois anos em que o estudo foi conduzido (Tabela 1). OLIVEIRA (2000), ao estudar a flutuação populacional de $\boldsymbol{D}$. maidis em armadilhas adesivas no município de Anastácio, MS, também observou que as armadilhas adesivas instaladas a $0,5 \mathrm{~m}$ coletaram mais indivíduos do que as posicionadas a 1,5m de altura, tanto nas áreas de cultivo de milho como em pastagens.

Com base nos resultados obtidos nesta pesquisa, pode-se inferir que a cigarrinha-do-milho, $\boldsymbol{D}$. maidis, apresenta dois picos populacionais na região de Dourados, sendo um observado no período da entressafra (julho a setembro) e outro no período de verão (dezembro a janeiro). Concluiu-se também que as armadilhas adesivas quando instaladas na altura 0,50m, a partir do nível do solo, capturam maior quantidade de cigarrinhas do que a $1,5 \mathrm{~m}$, sendo, portanto, esta altura mais adequada para o monitoramento dessa praga na cultura do milho.

Tabela 1 - Número médio de cigarrinhas, Daubulus maidis, capturadas/armadilha em duas alturas na cultura do milho de duas localidades e em gramado.

\begin{tabular}{llc}
\hline Local de amostragem & $\begin{array}{c}\text { Altura de instalação da } \\
\text { armadilha (m) }\end{array}$ \\
& 0,50 & 1,50 \\
\hline Lavoura de milho (Dourados) & $17,5^{*}$ a & $5,8 \mathrm{~b}$ \\
Lavoura de milho (Ponta Porã) & $4,6 \mathrm{a}$ & $1,6 \mathrm{~b}$ \\
Gramado (Dourados) & $7,3 \mathrm{a}$ & $4,2 \mathrm{~b}$ \\
\hline
\end{tabular}

*Médias não seguidas da mesma letra, na linha, diferem estatisticamente entre si pelo teste de t ao nível de $5 \%$ de probabilidade de erro.

Ciência Rural, v.38, n.4, jul, 2008. 


\section{REFERÊNCIAS}

BUSHING, R.W.; BURTON, V.E. Leafhopper damage to silage corn in California. Journal of Economic Entomology, v.67, n.5, p.656-658, 1974 .

HERNANDEZ-VAZQUEZ, S. et al. Densidad estacional de Daubulus maidis (Homoptera: Cicadellidae) en maiz (Zea mays) y en el teosinte perenne (Zea diploperennis) (Graminae). Folia Entomologica Mexicana, n.86, p.15-24, 1992.

HRUSKA, A.J.; PERALTA, M.G. Maize response to corn leafhopper (Homoptera: Cicadelidae) infestation and achaparramiento disease. Journal of Economic Entomology, v.90, n.2, p.604-610, 1997.

MOYA-RAYGOZA, G. Dinâmica poblacional de Daubulus spp. (Homoptera: Cicadellidae) en maiz (Zea mays) (Graminae) y sus parientes cercanos. Folia Entomologica Mexicana, n.87, p.21-29, 1993.

NAULT, L.R. Evolution of insect pest: maize and leafhopper, a case of study. Maydica, v.35, n.2, p.165-175, 1990.

NAULT, L.R. Mayze bushy stunt and corn stunt a comparison of disease symptons; pathogens host ranges, and vectors. Phytophatology, v.70, n.7, p.659-662, 1980.
OLIVEIRA, C.M. de. Variação morfológica entre populações de Dalbulus maidis (DeLong \& Wolcott, 1923) (Hemiptera: Cicadellidae) de algumas localidades do Brasil. 1996. 69f. Dissertação (Mestrado em Ciências) Escola Superior de Agricultura “Luiz de Queiroz”, Universidade de São Paulo, Piracicaba.

OLIVEIRA, C.M. de. Variação genética entre populações de Dalbulus maidis (DeLong \& Wolcott, 1923) (Hemiptera: Cicadellidae) e mecanismos de sobrevivência na entressafra do milho. 2000. 167f. Tese (Doutorado em Ciências) - Escola Superior de Agricultura "Luiz de Queiroz", Universidade de São Paulo, Piracicaba.

OLIVEIRA, C.M. de; LOPES, J.R.S. Cigarrinha-do-milho: aspectos taxonômicos e ecológicos, sobrevivência na entressafra. In: OLIVEIRA, E. de; OLIVEIRA, C.M. de (Ed.). Doenças em milho: molicutes, vírus, vetores e mancha por Phaeosphaeria. Brasília, DF: Embrapa Informação Tecnológica; Sete Lagoas: Embrapa Milho e Sorgo, 2004. Cap.3, p.61-88.

OLIVEIRA, E. et al. “Enfezamento pálido” e "Enfezamento vermelho" na cultura do milho no Brasil Central. Fitopatologia Brasileira, v.23, n.1, p.45-47, 1998. 